\title{
a sopa ao "pistou" ou a construção de um objeto de valor ${ }^{1}$
}

\author{
Algirdas Julien Greimas
}

\author{
SOPA AO "PISTOU" \\ "Para 8 pessoas: \\ 6 litros de água, \\ $1 \mathrm{k}$ de feijão de fava \\ (brancos, ainda frescos) a serem debulhados, \\ $350 \mathrm{~g}$ de vagens com grãos já formados, \\ 6 batatas, 6 cenouras, 4 alhos-porós, \\ 4 tomates, 6 abobrinhas, 2 ramos de sálvia, \\ 3 maços de manjericão, 6 dentes de alho, \\ $300 \mathrm{~g}$ de parmesão não-ralado, \\ 6 colheradas de azeite de oliva na sopa."
}

H. PHILIPPON, La Cuisine Provençale.

ABSTRACT: The translation of Greima's "La soupe au pistou" is justified by the importance of such analysis, which was done in 1979. In "La soupe au pistou" Greimas exemplifies a different kind of value acquisition performance: the construction of the object as the place of investment of the desired value.

KEY WORDS: Performance - Acquisition - Construction - Object - Competence.

1. Texto traduzido, com a autorização da direção editorial francesa, de GREIMAS, A. J. La Soupe au Pistou ou la Construction d'un Objet de Naleur. Documents de Recherche du Groupe de Recherches Sémio-linguistiques, n. 5, Paris, 1979. 


\section{Algirdas Julien Greimas}

A sopa ao "pistou"2 é o que há de melhor na cozinha provençal. É o toque vencedor que o deixa estupefato de admiração gastronômica. É uma iguaria digna dos deuses. Uma iguaria, sim, bem mais do que uma sopa.

Durante muito tempo acreditei que a sopa ao "pistou" fosse de origem genovesa e que os provençais, ao incorporarem-na, simplesmente haviam melhorado bastante. Mas meu amigo Femand Pouillon explicoume que a sopa ao "pistou" era um prato nacional iraniano! Pouco importa, pois no momento em que todo mundo a aprecia na Provença, naturalizemo-la provençal.

Bem-entendido, não existe uma só e única receita de sopa ao "pistou" adotada, definitivamente, pelos provençais. Pode-se citar uma boa dúzia delas. Eu experimentei todas. Aquela que prefiro, e de longe, é a que eu tive a audácia de chamar de "minha sopa ao "pistou" Para minha grande confúsão, devo reconhecer que não füi eu que inventei a receita. Eu a obtive de uma amiga provençal, na casa da qual tomei pela primeira vez uma sopa ao "pistou" prodigiosa, aquela mesma que vou lhe dar a receita.

Mas antes, devo insistir sobre um ponto: esta receita só é válida para oito pessoas, isto é, as proporções foram estabelecidas para oito pessoas e não mais.

O melhor seria utilizar uma panela de barro de Vallauris (França). Mas, a rigor, não importa qual a panela que possa executar a tarefa.

Então, você -coloca seis litros de água na panela de barro provençal, salgue e apimente logo em seguida.

Debulhe $1 \mathrm{k}$ de feijão de fava e faça cozinhar os feijões à parte, numa caçarọla de água fervendo. Descasque em seguida seis batatas de tamanho médio e corte-as em pequenos cubos.

2. O "pistou" é um creme de manjericão (planta aromática) e alho, esmagados em azeite de oliva. De origem italiana, conhecemos, por exemplo, a macarronada ao "presto". (N.T.) 
Depois, tire a pele e as sementes de quatro tomates.

Lave em água corrente $350 \mathrm{~g}$ de vagens com grãos já formados e corte-as em pedacinhos, depois de ter retirado os fios.

Raspe ainda seis cenouras de grossura média e corte-as em cubos. Pegue, finalmente, quatro alhos-porós dos quais você só deve utilizar o branco: lave-os e corte-os em rodelas.Quando a água da panela ferver, adicione os feijões que começaram a cozinhar à parte.

Adicione os tomates e as batatas, assim como as seis abobrinhas, que você já deve ter descascado e cortado em cubos.

Acrescente, finalmente, dois ramos de sálvia.

Quando tudo recomeçar a ferver, abaixe o fogo e deixe cozer a fogo moderado por duas horas.

Cerca de meia hora antes de servir, ajunte os alhos-porós e as vagens verdes em pedaços, assim como macarrão vermicelle (ou macarrão com a forma de minúsculos cotovelos).

Enquanto a sopa cozinha, você terá bastante tempo de fazer o "pistou" propriamente dito. Porque eu ia esquecendo de lhe informar: a sopa ao "pistou" é uma sopa de legumes à qual se acrescenta, no último momento, uma espécie de pomada odorante - o "pistou" - que lhe dá mais do que espírito: gênio. Num almofariz ${ }^{3}$ grande, de mármore ou de madeira de oliveira, você mói dois ou três maços de folhas de manjericão (se possível, manjericão da Itália, de folhas grandes), com seis dentes grandes de alho da Provença (pois é bem mais doce do que o alho colhido no resto da França), e $300 \mathrm{~g}$ de parmesão cortado em finas fatias (só o fato de ralá-lo já muda o sabor da sua sopa).

3. Almofariz é um recipiente de pedra, metal, madeira, etc., em que se trituram e homogeneizam substâncias sólidas. Muito usado em farmácias antigas, farmácias de manipulação etc. (N.T.) 
Você obtém, com muito trabalho e paciência, uma pomada (ungüento) 4 que você rega, durante o preparo, com cinco ou seis colheradas de azeite de oliva.

Finalmente, logo que sua sopa estiver pronta, você a retira do fogo, mas, antes de juntar o "pistou", convém esperar que a sopa deixe de ferver completamente. Para isso, é recomendável misturar o "pistou" no almofariz com uma ou duas conchas grandes da sopa. Depois você joga tudo na panela, mexendo rapidamente. Essa operação impedirá o azeite do "pistou" de talhar. Por fim, coloque sua sopa numa sopeira e a sirva.

\section{A Receita de Cozinha}

A receita de cozinha, embora formulada, na superfície, com a ajuda de imperativos, não pode ser considerada como uma prescrição, regida por um /dever-fazer/ subentendido no conjunto do texto. Ela se apresenta antes como uma proposição de contrato do tipo: "Se você executar corretamente o conjunto de indicações dadas, você obterá a sopa ao 'pistou"” Trata-se, portanto, de saída, de uma estrutura actancial pondo em presença dois sujeitos - o destinador e o destinatário - situados ambos sobre a dimensão cognitiva: o destinador, normalmente encarregado de modalizar o destinatário, não se preocupa muito em lhe transmitir um /querer-fazer/ nem um /dever-fazer/, contentando-se em investi-lo da modalidade do /saber-fazer/. Desse ponto de vista, a receita de cozinha não se distingue, por exemplo, da lei sobre a interrupção voluntária da gravidez (precedentemente analisada no seminário) que, não obstante seu status aparente de lei, apresenta-se como um percurso sabiamente programado de atos a cumprir, elaborado tendo em vista as mulheres desejosas de interromper sua gravidez, sem comunicar para tanto qualquer /dever-/ ou /quererfazer/. Tanto num caso como no outro, as modalizações aparentes, manifestadas na superfície discursiva, não correspondem ao estatuto modal do texto revelado pela análise.

\footnotetext{
4. É interessante que o autor usou "pommade" e não "crème" ou "pâte", por exemplo, sinalizando uma isotopia alquímica. (N.T.)
} 
É a aceitação desse contrato implícito que desencadeia o fazer culinário e permite situar a passagem do cognitivo ao pragmático, da competência ao desempenho. O /saber-fazer/, considerado como um dos componentes da competência do sujeito e que fica subentendido e pressuposto nos comportamentos quotidianos dos homens, acha-se aqui não somente explicitado, mas, por uma espécie de rodeio que o desvia de sua finalidade que é a passagem ao ato, manifestado sob a forma de um discurso particular. A receita de cozinha pode, por conseguinte, ser considerada como uma subclasse de discursos que, analogamente às partituras musicais ou aos projetos do arquiteto, apresentam-se como manifestações de competência atualizada, anteriormente à sua realização.

Embora o texto da receita comporte numerosos elementos do fazer persuasivo, o mesmo não constitui a razão decisiva da aceitação do contrato. A aceitação, enquanto assunção do /saber-fazer/, integra-se num PN (programa narrativo) já elaborado, suscitado seja por um /quererfazer/ - convite endereçado aos amigos, por exemplo -, seja por um /dever-fazer/ - necessidade de alimentar sua família. O destinatário da receita de cozinha é, em conseqüência, já um sujeito modalizado (S,), de posse de um programa a realizar. O fazer persuasivo desempenha apenas um papel secundário, no momento da escolha de tal ou qual receita; ainda mais, ele se situa num outro nível, naquele do programa do autor preocupado em vender seu livro de receitas. Também, na análise que segue, não levaremos isso em conta.

O PN em questão - que chamaremos de $P N$ de base - consiste na atribuição, por S,, do objeto de valor $\mathrm{O}$, "a sopa ao pistou", ao sujeito de estado $\mathbf{S}_{2}$, "os convidados"”

$$
\mathrm{PN} \text { de base }=\mathrm{Sj} \text {-* }\left(\mathrm{S}_{2} \text { o } \mathrm{O}: \text { sopa }\right)
$$

É no quadro constituído por esse $\mathrm{PN}$ de base que se inscreverão os outros PNs, considerados como PNs de uso ou de auxílio. 


\section{O Objeto e o Valor}

Para que S, possa transmitir o objeto de valor "sopa" é preciso que ele o possua antes. Ora, a posse não pode ser assegurada senão pela ajuda de um $P N$ de doação (efetuado pelo destinador), de um $P N$ de troca (encomenda a um comerciante que prepara o prato feito) ou, finalmente, de um $P N$ de produção. É a este último caso que corresponde a realização da receita de cozinha.

Um programa de produção consiste na construção de um objeto de valor, isto é, de um objeto no qual seja investido um valor cuja conjunção com $\mathrm{S}_{2}$ seja suscetível de aumentar o seu ser. Esse valor pode corresponder, no nosso caso, à satisfação de uma necessidade, ou à procura de um prazer. Não sendo, de modo geral, as receitas de cozinha redigidas pensando em pessoas que morrem de fome, pode-se admitir que o valor investido consistirá numa sensação gustativa eufórica. Sendo as pessoas convidadas para sentir um prazer estético de ordem gustativa, o valor a produzir deverá fazer parte do código gustativo cultural implícito.

Tal valor, relativamente abstrato, é investido num objeto figurativo complexo denominado "sopa ao pistou" cuja construção exige a execução de um conjunto de programas somáticos e gestuais. O PN de construção, sendo um $P N$ de uso inserido no PN de base, terá portanto a forma de um percurso de ordem figurativa. Sendo assim, a comparação se apresenta por ela mesma: embora o conto maravilhoso proppiano - e as extrapolações às quais ele dá lugar - apareça como podendo servir de modelo de $P N$ de construção de sujeitos, um trabalho paralelo deveria ser promovido para elaborar os modelos de $P N$ de construção de objetos.

É situando o PN de construção no nível figurativo dos discursos que se explica a importância de sua articulação temporal. O cozimento dos elementos destinados a constituir a sopa é um processo durativo, comportando, além disso, um aspecto tensivo que o dirige para o acabamento: a construção do objeto apresenta-se em termos de estruturação aspectual. O que, no plano lógico, é interpretado como a transformação de um estado em outro estadó (da "não-sopa" em "sopa"), formulado aqui em termos de 
tomar-se: os diversos ingredientes "tomam-sc" uma sopa.

A introdução da temporalidade. que tem por efeito converter os programas em processos, permite apreender naturalmente um dos aspectos definidores da programação que consiste:

a) na elaboração de uma série de implicações entre enunciados e programas narrativos, logicamente necessários à realização do $\mathrm{PN}$ de base;

b) na conversão dessa série de implicações numa série temporal de processo.

\section{O Dispositivo Estratégico}

A leitura superficial do programa culinário já permite reconhecer, no seu nível pragmático (não-realizado), a existência de dois PNs paralelos e independentes, cuja conjunção, no final do percurso, constitui o PN de construção global. Dois objetos parciais serão construídos com a ajuda dos programas:

$$
\begin{aligned}
& \mathrm{PN},=\text { confecção da "sopa de legumes" c } \\
& \mathrm{PN},=\text { = confecção do "pistou propiamente dito", }
\end{aligned}
$$

para constituir em seguida, pelos procedimentos de "mistura" e de "fusão" um objeto de valor único: a "sopa ao pistou" distinguir ali:

O exame de cada um desses programas permite, por seu lado.

a) um $P N$ principal (que começa, para o $\mathrm{PN}$, por "jogue 6 litros de água..." ·

b) uma série de PNs adjuntos (tais como: "descasque 6 batatas..." "tire a pele e as sementes de 4 tomates..." etc.). 


\section{Algirdas Julien Greimas}

\section{A sopa de legumes}

O PN, principal ó rcconhccívcl:

a) pela atribuição que lhe é feita de um espaço autônomo: a "panela" que pode ser considerada como um espaço utópico, lugar das principais transformações do /cru/ em /cozido/ A "panela" espaço próprio do $\mathrm{PN}_{1}$, opõe-se o "almofariż" espaço autônomo do PN,(o estatuto do terceiro reçipiente, a "caçarola" será examinado mais tarde);

b) pela adição a esse espaço de um actante sujeito, "água" que será instituído como operador das transformações - é a água, com efeito, que "faz cozinhar" os legumes;

c) pela "desnaturalização" da água. A instrução "salgue e apimente logo em seguida" marca bem a passagem da água do estado de /natureza/ ao estado de /não-natureza/;

d) pela aparição implícita do sujeito "fogo" que cumpre uma dupla função: colocando a água em ebulição, ele a qualifica como sujeito operador (para fazer cozer os legumes); agindo diretamente sobre a águaobjeto. ele a transforma em objeto consumível (a massa já c uma sópa).

Vê-se que as operações que se realizam no espaço utópico aproximam o fazer culinário aparentemente racionalizado do modelo mítico da transformação do $\mathrm{cru} \mathrm{cm}$ cozido, antropomorfizando. notadamente. os elementos da natureza, e nisso instaurando-os como sujeitos operadores.

Vê-se, por outro lado, que se o realizador humano do programa culinário aprcscnta-sc como um "mestre cuca" ele delega rapidamente seus poderes a outros sujeitos de fazer (o fogo faz ferver a água; a água faz cozer os legumes), instaurando assim estruturas de manipulação em que os sujeitos delegados, estreitamente controlados (pela atribuição, notadamente. do tempo de cozimento próprio de cada legume, isto é, pelo estabelecimento da correspondência entre os processos durativos de 
cozimento e as transformações lógicas do /CRI/ em /cozido/), parecem agir por mandato imperativo.

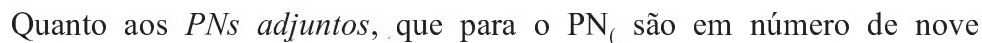
e que são formulados, no interior da receita, como estes, por exemplo:

"tome quatro alhos-porós (só utilize o branco)“

"lave-os"

"corte-os em rodelas"

vê-se que sua razão de ser reside na transformação de objetos crus em objetos não-crus. sendo só esses objetos "scmiculturalizados" em seguida. integrados ao PN principal, submetidos ao cozimento e à transformação em objẹtos cozidos. As duas operações são assim distintas:

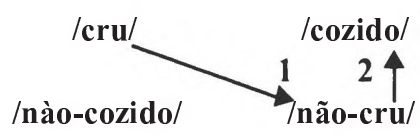

a primeira podendo ser efetuada com a ajuda dos PNs adjuntos, enquanto a segunda, operação de síntese, cumpre-se no quadro do PN principal. É perfeitamente natural que os PNs adjuntos façam pensar, nos casos da construção de sujeitos, nos desempenhos decisivos dos sujeitos.

Notar-se-á também que a realização dos PNs adjuntos, atribuída pelo nosso texto ao próprio mestre-cuca e exigindo, por isso. uma programação temporal das tarefas, pode também ser confiada a sujeitos delegados (humanos ou autômatos). No entanto, a ordem de sucessão dos PNs adjuntos, malgrado a aparência de uma consecução textual exigida pela sua enumeração, não se acha precisada aqui - não seria obrigatório que fosse fundamentada sobre uma série de implicações lógicas. É de se supor que os programas de constRição de objetos mais complexos que o nosso comportariam prescrições de execução de tarefas previstas de início.

significação $11 / 12$ 


\section{Algirdas Julien Greimas}

Tal organização dc substituições, reconhecível sobre os eixos programáticos paralelos, cujos resultados, sob a forma $\mathrm{dc}$ objetos semiacabados, acham-se progressivamente integrados no $\mathrm{PN}$ principal, presta conta finalmente da constituição e do funcionamento daquilo que designamos de um outro ponto de vista como sujeito coletivo sintagmático (citando a esse propósito as usinas Renault). Resta ver, evidentemente, em quais condições um esquema de programação, desde o momento em que sua execução se torna iterativa, é suscetível de engendrar uma instituição (uma empresa).

Dentre os PNs adjuntos, há um que se distingue dos outros pelo seu caráter semi-autônomo. Com efeito, este programa: "debulhe $1 \mathrm{k}$ de feijão de fava, faça-os cozer à parte numa caçarola com água fervendo" "quando a água ferver na panela, jogue os grãos de feijão que começaram a cozinhar à parte'" é ao mesmo tempo:

a) independente, pelo fato de possuir seu próprio espaço utópico (a "caçarola"), seus próprios sujeitos delegados manipuladores (o fogo e a água);

b) adjunto, porque o objeto scmi-construído por esse programa (os feijões que começaram a cozinhar à parte) acha-se integrado, ao mesmo tempo que os outros objetos não-crus, no PN principal.

À primeira vista, é o tempo de cozimento, mais longo que para os outros legumes, que determina só a ele a autonomia desse PN adjunto. E evidente, desse ponto de vista, que a receita de cozinha é mal-redigida: a água da caçarola já deve estar fervendo no momento em que começa a execução do PN principal. Entretanto, a estrutura formal desse PN não se distingue em nada dos PNs independentes; possui mesmo, com exclusão de qualquer outro, um PN adjunto "debulhe os feijões de fava" $O$ que se parece produzir aqui é um desvio do PN visando obter um objeto de valor próprio, "os feijões cozidos" e a sua integração num dispositivo funcional mais vasto e distinto: preparar uma sopa de legumes. Tal subordinação do PN independente só pode nos lembrar dos procedimentos de integração dos "motivos" suscetíveis de funcionar como prescrições autônomas, nas estruturas narrativas mais vastas. 


\section{O "pistou"}

$\mathrm{O} \mathrm{PN}_{2}$, visando a confecção do "pistou" propriamente dito, possui, malgrado sua aparente simplicidade, uma independência real que the é garantida pela sua situação no espaço utópico próprio, o " "almofariz" e ainda pela realização completa de seu objeto de valor, o "pistou" que só é ajuntado e misturado com a sopa de legumes no instante $\mathrm{cm}$ que "ela pára inteiramente de ferver"

Sua autonomia lhe vem, por outro lado, da originalidade das técnicas efetuadas tendo em vista a confecção do objeto: enquanto, no PN, a panela ć no início enchida d'água, isto é, de um líquido que trata de solidificar, a execução do $\mathrm{PN}$, consiste $\mathrm{cm}$ pôr em ação os produtos sólidos para os liquefazer. A realização dos dois PNs converge quase ao mesmo ponto e a fusão dos dois objetos produz o objeto complexo líquido e sólido que é a sopa ao "pistou"

O PN, principal apresenta-se igualmente muito diferente do PN,. enquanto no primeiro caso o fazer culinário básico era imediatamente delegado ao fogo e à água, instituindo-os por isso como sujeitos manipuladores, a operação culinária, exigindo a presença de um sujeito humano, é aqui dupla: ela consiste na trituração ("moa") dos objetos sólidos; no seu regar iterativo com o azeite de oliva (líquido).Quanto aos ingredientes que constituem, de saída, o conteúdo do almofariz, pode-se. do ponto de vista de suas qualificações para entrar na composição do objeto cultural a ser construído, agrupá-los em duas classes:

a) o azeite de oliva e o parmesão (aos quais é preciso juntar o vermicelle do $\mathrm{PN}$,) já são inteiramente objetos culturais, possuidores de uma história e de um PN de construção completos. O PN adjunto ao qual se acha submetido o parmesão ("cortado em finas fatias" c não "ralado") é portanto uma operação redundante do ponto de vista de sua "culturalização" .

b) o manjcricão c o alho (aos quais é preciso juntar dois ramos de sálvia do $\mathrm{PN}$,) não deixam de oferecer problema. A primeira impressão 


\section{Algirdas Julien Greimas}

liberada pela leitura da receita c' que scu estatuto "natural" e, por isso. nño-qualificado acha-se camuflado por urna retórica textual:

- "três maços de folhas de manjericão (tanto quanto possível manjericão da Itália de folhas grandes)":

- "seis dentes grandes de alho da Provença (porque é muito mais doce do que o alho colhido no resto da França)"'

Tudo se passa, todavia, como se todo produto proveniente do Exterior. fato que implica operações de transporte, se encontrasse já valorizado, suscetível de ser considerado como um objeto ñao-natural constatação que ultrapassa, como se vê, o reconhecimento dos embelezamentos retóricos c que remete à questão, diferentemente importante, do estatuto cultural dos condimentos.

Entrevendo no seu conjunto as grandes linhas que permitem apreender esse tipo particular do fazer culinário - procedimentos que partem da decomposição dos objetos parciais, servem-se de sua liquefação progressiva e chegam à recomposição de um objeto complexo novo (a "pomada") é, para nós impossível imaginar, no estado atual, o modelo que levaria $\mathrm{cm}$ conta a construção desse gênero de objetos culturais. Um melhor conhecimento da obra teórica dos alquimistas poderia provavelmente jogar ali alguma luz. Tratar-se-ia, em suma. de inventariar um número limitado de processos tecnológicos elementares cuja combinação cobriria o conjunto dos fazedores de objetos culturais.

\section{A programação 5}

Estamos agora em condição de propor a representação do conjunto dos procedimentos de construção da "sopa ao pistou" sob a forma de um esquema de programação:

\footnotetext{
5. Para os PNs adjuntos ( $\left.\mathrm{PN}_{\text {, a }} \mathrm{PN}_{\mid}\right)$, Greimas usa a notação de elemento matricial, por exemplo, o PN é,o segundo adjunto do $\mathrm{PN}_{(}$, o $\mathrm{PN}_{(\mathrm{J}}$ é o terceiro adjunto do $\mathrm{PN}_{(}$e assim por diante. (N.T.)
} 


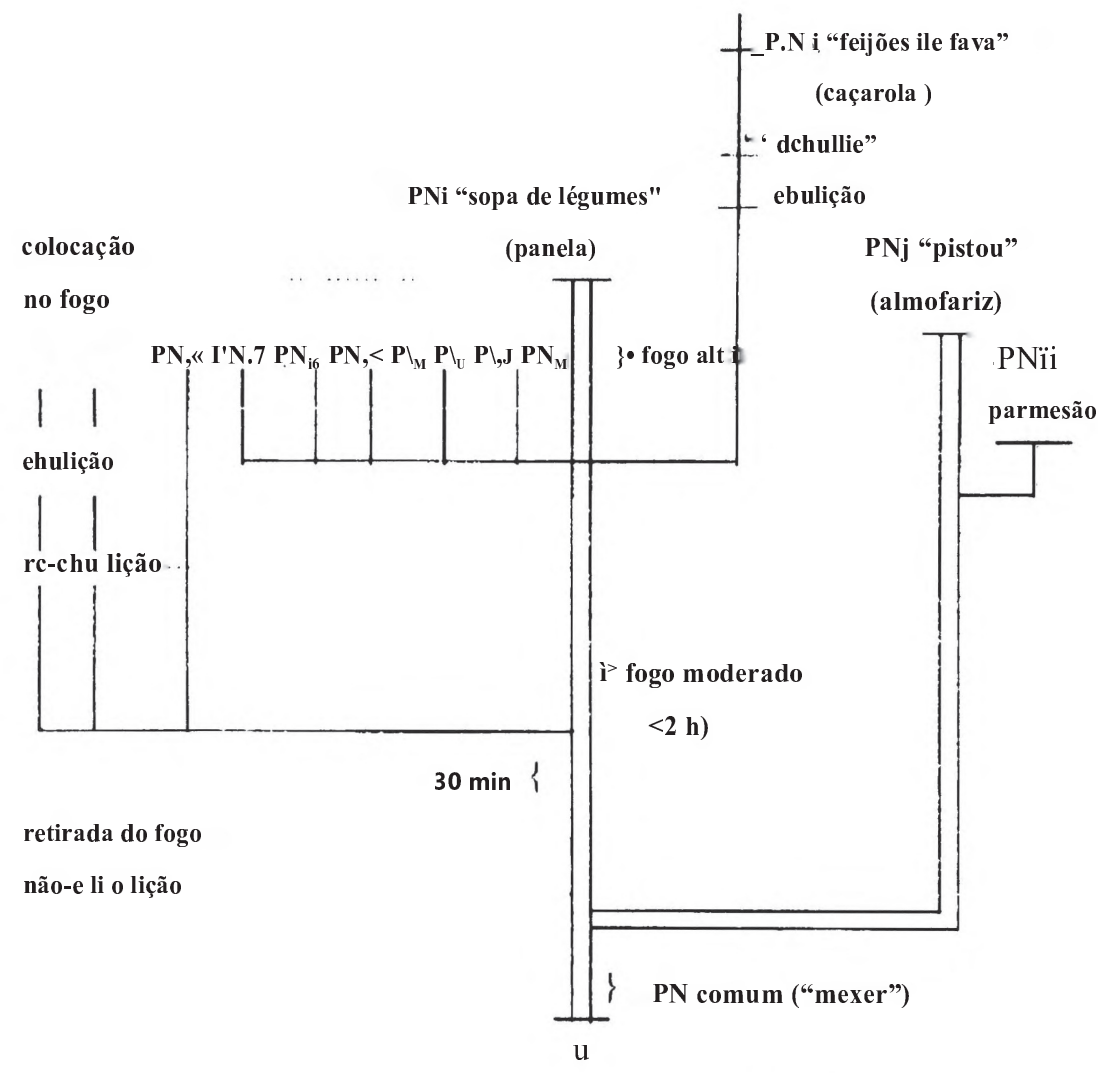

PN de base: S| -> PN de uso ("sirva")

$\rightarrow \mathrm{S} \geq$ (convidados)

4. Alguns Ensinamentos

Ao término desse exame bastante superficial de um texto nãohabitual. convém ressaltar, o que seria apenas para justificar sua escolha, alguns ensinamentos de caráter mais geral.

Nós conseguimos, nos parece, situar os textos chamados "receitas de cozinha" no interior de uma classe de discursos mais vasta, aquela dos discursos programadores, que podem ser considerados como manifestações discursivas c um dos componentes da competência modal do 
sujeito, aquela do /sabcr-fazer/, manifestações de desvio pelo fato de que elas interrompem o percurso narrativo do sujeito anteriormente à sua passagem ao ato executor e cindem assim o sujeito $\mathrm{cm}$ dois actantes: um destinador-programador c um destinatário-rcalizador, instituindo o primeiro no papel de narrador.

Caso se considere o ato como justificador da estrutura modal do /fazer-scr/, vê-se que o fazer em questão é suscetível de apelar à existência. seja dos sujeitos, seja dos objetos. A semiótica narrativa, particularmente sensível à construção do sujeito, até o presente tem desleixado completamente a problemática da constniçció do objeto. O texto examinado apresenta-se justamente como o projeto de construção de um objeto particular, a "sopa ao pistou" Inversamente, o objeto, considerado como o resultado de uma atividade produtora, é suscetível de receber uma definição generativa que a leva em conta pelo seu modo de construção. $\mathrm{O}$ projeto semiótico. como se vê, deve colocar em ação a elaboração dos modelos de ordem generativa (e não genética), aproximando-se. por esse fato, da pesquisa dita operacional, cujo caráter "aplicado"' e a linha dc horizonte principal - a otimização dos procedimentos de geração - não devem escapar-lhe.

A manifestação discursiva da estrutura modal do /saber-fazer/, que se fixou essencialmente como um procedimento dc programação, nos ensina algo sobre o funcionamento dessa "inteligência sintagmática" que fica o mais das vezes implícita e pressuposta pelo ato. Observa-se em particular que a programação global efetua-se a partir do ponto terminal do processo imaginado e consiste, partindo da meta fixada, na procura e na elaboração dos meios para ali chegar, isto é, remontando o tempo e não se deixando apartar dele. É apenas numa segunda fase que se opera a temporalidade dos programas narrativos e o estabelecimento da ordem de sua sucessão. Eis um argumento de peso, se ainda há necessidade dele. contra certas teorias narrativas que fundamentam a articulação da narratividade na sucessão temporal.

O caráter lógico da programação explica, por seu lado, o lugar particular que ocupa a construção de objetos no PN básico: o essencial 
para o homem é a procura e a manipulação dos valores (sua apropriação, sua atribuição etc.); os objetos não lhe interessam - e sua construção não merece ser empreendida - a não ser na medida em que eles constituam lugares de investimentos dos valores. Também o nível lógico-semântico, em que se reconhecem e circulam os valores, deve ser considerado como mais profundo do que aquele, figurativo, em que se constroem e/ou se trocam os objetos.

O esquema de programação, tal como acabamos de apresentar, malgrado sua simplicidade - ou por causa dela -, pode ser considerado como uma amostra sugestiva que permite que se faça uma idéia do que é a organização semiótica narrativa em geral. Um discurso narrativo, qualquer que seja sua complexidade, é, do ponto de vista do enunciador, um objeto construído e, do ponto de vista do enunciatário, um objeto suscetível de receber uma definição generativa.

Tradução de Edith Lopes Modesto

Universidade de São Paulo e Universidade Mackenzie 